\title{
A EDUCAÇÃO AMBIENTAL NO CONTEXTO DE UM PARQUE ECOLÓGICO NO INTERIOR DE SÃO PAULO
}

Lorena Jorge Lorenzi ${ }^{1}$

Nathalia Bianca Aparecida Sposito Barbosa²

Adriele Evelyn Ferreira da Silva ${ }^{3}$

Yasmin Mansur Salman ${ }^{4}$

Resumo: A Educação Ambiental (EA) proporciona uma consciência crítica quanto à preservação do meio ambiente. Assim, este estudo teve como objetivo verificar a percepção acerca de um parque ecológico junto aos seus funcionários e visitantes, bem como sensibilizar quanto a preservação ambiental. Foram realizadas entrevistas de forma aleatória aos funcionários $(n=9)$ e visitantes $(n=30)$, além de uma ação de EA com visitantes $(n=13)$. A avaliação do local foi positiva, porém sendo citada possível melhora na gestão e infraestrutura. A ação de EA foi considerada importante para conscientização acerca do meio ambiente. Os resultados deste estudo podem auxiliar no desenvolvimento de ações de EA, além de ajudar na gestão do parque.

Palavras-chave: Meio Ambiente; Educação Ambiental; Consciência Ambiental; Parque Ecológico; Zoológico.

Abstract: Environmental Education (EE) provides a critical awareness regarding the preservation of the environment. Thus, this study aimed to verify the perception about an ecological park with its employees and visitors, as well as raise awareness about environmental preservation. Interviews were carried out at random to employees $(n=9)$ and visitors $(n=30)$, in addition to an EE action with visitors $(n=13)$. The evaluation of the site was positive, but possible improvement in management and infrastructure was mentioned. The EE action was considered important for raising awareness about the environment. The results of this study can assist in the development of EE actions, in addition to helping in the management of the park.

Keywords: Environment; Environmental Education; Environmental Awareness; Zoo; Ecosystem.

\footnotetext{
${ }^{1}$ Universidade Federal de São Carlos. E-mail: Iololorenzi@hotmail.com.

2 Universidade Federal de São Carlos. E-mail: natalia-sposito@hotmail.com

3 Universidade Federal de São Carlos. E-mail: adrieleferreirasilva@gmail.com

${ }^{4}$ Universidade Federal de São Carlos. E-mail: yasmin_m_salman@hotmail.com
} 


\section{Introdução}

A Educação Ambiental (EA) foi definida, na Conferência de Tbilisi em 1997, como uma interface dada entre o conteúdo e a prática de educação, que visa garantir a todas as pessoas a oportunidade de adquirir conhecimentos, o sentido dos valores, 0 interesse ativo $e$ as atitudes fundamentais para protegerem e melhorarem o meio ambiente (BARRETO; GUIMARÃES; OLIVEIRA, 2009).

Além disso, o Conselho Nacional do Meio ambiente, define a EA como um processo de formação e informação, voltado ao desenvolvimento da consciência crítica, sobre assuntos ambientais e de atividades que propiciem à participação das comunidades na preservação do equilíbrio ambiental (DIAS; DIAS, 2017).

Segundo Dias (2003), a EA tem como meta fazer com que a população evolua, tenha consciência e preocupação com o meio ambiente e com os problemas que o circundam, e tenham a disposição e pró atividade para trabalhar, individualmente ou coletivamente, na busca de soluções para tais problemas. Assim, a EA por meio do diálogo e da inclusão, pode incentivar mudanças de comportamento a fim de construir sociedades sustentáveis (GRAJAL et al., 2016; RANCURA et al., 2016).

Segundo Furtado e Branco (2003), atualmente o contato entre as áreas de preservação e os acessos naturais básicos tornaram-se distante da maioria da população. Desse modo, a EA vem como uma estratégia para recuperar a saúde global, tendo como premissa básica a educação, no qual os valores e as atitudes devem estar adequados com a ética ambiental (FURTADO; BRANCO, 2003).

De acordo com Hsu (2017) e Moss, Jensen e Gusset (2015) a EA deve ser realizada em diferentes ambientes explorando os recursos presentes, assim, alguns locais estratégicos para realização da mesma são parques, museus, aquários e zoológicos, pois possuem um grande potencial para alcançar diferentes indivíduos e conscientizá-los.

Segundo IBAMA (2005), os zoológicos, por conta da sua diversidade biológica, são estratégias utilizadas pelos educadores ambientais para informar e conscientizar os visitantes acerca da importância da preservação do meio ambiente. Eles são espaços favoráveis para a realização de ações de Educação Ambiental, pois possibilitam a observação e proporcionam a construção de um conhecimento dinâmico. Além disso, para que os mesmos funcionem com qualidade, faz-se necessário entender os anseios e preocupações do público visitante, de modo que mantenha a conservação ambiental, o que, consequentemente, exige planejamento e gestão dessa área (BARRETOS; GUIMARÃES; OLIVEIRA, 2009; BARRETO et al., 2019).

É de extrema importância a EA em zoológicos, uma vez que que eles atraem um número grande de visitantes em todo o mundo e possuem um alto potencial para a sensibilização ambiental (ALMEIDA; FERNÁNDEZ; 
STRECHT-RIBEIRO, 2017). Assim, a realização de ações de EA em zoológicos pode promover o diálogo e a aprendizagem acerca do meio ambiente, a inclusão social dos visitantes e momentos de descontração e alegria, além de estimular o conhecimento sobre a vegetação e os animais presentes no local (FISCHER et al., 2017; RANCURA et al., 2016).

Além disso, ouvir atores sociais e a percepção dos mesmos, de forma a preencher lacunas que envolvem à participação social no âmbito da gestão ambiental, fornece subsídios e informações relevantes para que gestores desenvolvam políticas públicas, a fim de suprir a necessidade da sociedade e também da conservação ambiental nestes locais (BARRETO et al., 2019). Ademais, é importante que diferentes atores sociais sejam ouvidos e incluídos, partindo da minoria, envolvendo pessoas com deficiências, idosos, carentes de recursos financeiros, grupos em risco sociais, entre outros (FPZSP, 2015).

Sendo assim, é importante o desenvolvimento de ações de EA em zoológicos, para convencer gestores responsáveis por esses locais sobre a importância da mesma, além de contribuir para realização de pesquisas a fim de mostrar dados sobre o local, os animais, vegetações e visitantes (SILVA; GARCIA, 2019).

Portanto, o objetivo do presente estudo foi verificar a percepção de visitantes e funcionários de um parque ecológico no interior do estado de São Paulo sobre o mesmo, bem como sensibilizar acerca da importância da preservação do meio ambiente por meio de uma Educação Ambiental.

\section{Materiais e Métodos}

Trata-se de um estudo descritivo, qualitativo e de corte transversal, realizado em um Parque Ecológico no interior de São Paulo no ano de 2017.

O Parque Ecológico escolhido para realização do estudo foi o Parque Ecológico municipal Dr. Antônio Teixeira Vianna, no município de São Carlos, o qual foi fundado em 1976 e atualmente conta com uma extensão de 72 hectares e cerca de 500 animais de mais de 90 espécies, distribuídos em aproximadamente 90 recintos. O parque é especializado na fauna silvestre da América do Sul, principalmente com espécies em ameaça de extinção. Possui berçário para animais e um parque infantil, com playground para crianças e mesas para os visitantes realizarem piqueniques. Este recebe cerca de 120.000 visitas por ano (PRA TURISTA, 2019).

O estudo foi composto por duas etapas, o diagnóstico ambiental e ação de Educação Ambiental.

Para o diagnóstico ambiental foram realizadas duas visitas ao Parque Ecológico, a primeira feita em um dia durante a semana, na qual foram abordados de forma aleatória funcionários do parque que estavam presentes no momento, sendo selecionados os que aceitaram participar do estudo $(n=9)$. Realizou-se uma entrevista estruturada utilizando um questionário 
desenvolvido pelos pesquisadores, contendo aspectos relacionados ao trabalho e a satisfação com o mesmo, bem como a concepção deles sobre o que poderia ser melhorado no Parque Ecológico.

Os nove funcionários entrevistados possuíam diferentes ocupações no parque, sendo um biólogo, um estagiário, dois auxiliares terceirizados e cinco tratadores, totalizando três mulheres e seis homens, com idades entre 22 e 70 anos e média de 48,3 anos de idade, o tempo aproximado de trabalho no parque foi de média de 11 anos, variando desde funcionários que trabalhavam há 3 semanas, até funcionários que estavam no Parque há 25 anos.

A segunda visita ocorreu em um dia no final de semana (domingo), na qual foram abordados aleatoriamente visitantes que passaram pelo local entre o período de 9:00h à 12:00 nesse dia. Os que aceitaram participar do estudo $(n=30)$ responderam a um questionário, previamente desenvolvido pelos pesquisadores, com questões sobre vivências e sentimentos em relação ao local, percepções sobre modificações ao longo do tempo, aspectos que faltam e qualidades no mesmo.

A segunda parte do estudo trata-se de uma ação ambiental no próprio Parque, com os visitantes. Para a mesma, optou-se pela realização de uma roda de conversa com duração de 10 minutos, realizada pelo grupo de pesquisa envolvido no diagnóstico, com o objetivo de sensibilizar os visitantes acerca da importância da Educação Ambiental naquele espaço e como ela se relaciona com os animais e a vegetação que ali se encontram.

Os participantes dessa ação foram os visitantes que aceitaram participar ( $n=13$ ), os quais foram abordados de forma aleatória em uma terceira visita no parque durante o horário de 13:00h a 15:00h de um sábado, na qual foi explicada a proposta da ação e realizado o convite para participação na mesma.

Durante a roda de conversa foram realizados os seguintes questionamentos aos participantes:

- Qual o significado de Educação Ambiental?

- Qual a relação da Educação Ambiental com o espaço do Parque Ecológico?

- Quais são os animais que estão no Parque Ecológico, como chegaram e qual a importância deles no meio ambiente?

- Por que ser atuante na preservação ambiental e como fazer sua parte no Parque Ecológico?

A proposta da roda de conversa foi que todos pudessem participar e dar sua opinião sobre os tópicos, desse modo os pesquisadores realizaram as perguntas aos visitantes a fim de motivá-los a discutirem sobre os temas, além de incentivarem todos os participantes da roda de conversa a darem suas opiniões. Somado a esses temas, foram entregues folders desenvolvidos pelos 
pesquisadores, contendo tópicos sobre o significado de meio ambiente e da reciclagem e sobre a importância da preservação de espécies animais.

Ao final da ação educativa, foi realizado um feedback rápido com os participantes, a partir de um questionário de satisfação previamente elaborado, contendo perguntas sobre os seguintes tópicos: importância da ação, opiniões sobre a mesma e sugestões de modificações. Todos os participantes da ação responderam o questionário.

Sobre a escolha dos dias para as visitas realizadas ao Parque Ecológico para realização das duas etapas mencionadas da pesquisa, a primeira visita ocorreu em um dia durante a semana, pois de acordo com a coordenadora do parque a maioria dos funcionários estaria trabalhando nesse período e seria melhor para levantar informações com eles. Já a segunda e a terceira visita ocorreram em dias nos finais de semana, pois aos finais de semana há maior fluxo de visitantes.

Os dados colhidos foram digitados no programa Excel for Windows 2016, para a realização de análises descritivas e Análise Temática segundo Bardin (1977), a qual baseia-se nos discursos dos sujeitos de pesquisa, verificando a frequência dos temas mencionados e indicando modelos de comportamentos nos mesmos. Os dados foram contabilizados também em forma de média, frequência relativa e absoluta.

\section{Resultados}

\section{Diagnóstico}

Os nove funcionários entrevistados, ao serem questionados se gostavam de seu trabalho $78 \%$ das respostas foram positivas, enquanto $22 \%$ prefeririam estar em outro local.

Quando questionados sobre a razão de terem escolhido trabalhar no parque, $56 \%$ citaram as condições de trabalho, principalmente pela estabilidade, $22 \%$ relataram que escolheram pois gostam de trabalhar com animais. Dentre os entrevistados transferidos para o local $22 \%$ eram terceirizados e não escolheram trabalhar no parque.

Para a pergunta relativa aos pontos que poderiam ser melhorados no local, os mais citados foram a forma que a gestão é realizada (44\%), a necessidade de mais funcionários e a infraestrutura (44\%). $11 \%$ não responderam.

Em relação aos visitantes, a entrevista foi realizada com 30 pessoas, incluindo crianças, adolescentes, adultos e idosos, sendo que $17 \%$ tinha até 20 anos, $53 \%$ de 21 a 40 anos e $30 \%$ possuía mais que 40 anos.

Ao total, foram entrevistados 16 mulheres e 14 homens, sendo que desses, seis estavam visitando o parque pela primeira vez, 11 já o frequentam nos últimos 10 anos e 13 pessoas há mais de 10 anos. 
Quando questionados sobre como é o Parque Ecológico, a maior parte das respostas foi positiva, $77 \%$, fazendo referência à preservação da natureza e por ser um bom local de passeio para família. Já as negativas, $17 \%$ foram associadas principalmente à estrutura e manutenção, $6 \%$ não responderam.

Para a questão referente às qualidades do local, os visitantes citaram os animais $(30 \%)$, a vegetação $(20 \%)$, a infraestrutura $(20 \%)$, tudo no local $(13 \%)$ e a sua própria percepção pessoal (7\%), contudo alguns responderam o questionamento de forma negativa $(7 \%)$ e outros nem responderam $(3 \%)$.

Ao serem questionados se faltava algo no parque, $40 \%$ disseram que não faltava nada, 33\% relataram pontos negativos, sendo a maior parte em relação à infraestrutura do local, $23 \%$ não responderam e $3 \%$ não souberam responder.

$\mathrm{Na}$ questão sobre a importância do parque ecológico todos os visitantes entrevistados responderam de forma positiva, relacionando o parque à preservação da natureza, ao vínculo familiar nas visitas e ao momento de lazer vivenciado.

\section{Ação educativa}

Os participantes da ação educativa foram escolhidos de forma aleatória enquanto passavam pelo Parque Ecológico. Foram convidados a participar da roda de conversa, tendo como mediadores os membros do grupo de pesquisa. Ao todo, 13 pessoas participaram da ação, em momentos alternados, sendo seis homens $(n=6)$ e sete mulheres $(n=7)$, com idades entre 16 e 57 anos e média de 36,2 anos. Foram desconsideradas as crianças que estavam presentes, pois estas não responderam o questionário de satisfação e, portanto, não houve controle da quantidade em que estavam e demais dados das mesmas.

Quando questionados se viram importância na ação, todos os participantes forneceram respostas positivas, alternando o motivo entre: preservação do meio ambiente $46 \%$; conscientização $38 \%$; e conhecimento $15 \%$.

Todos os participantes responderam estar satisfeitos com a ação, citando tanto o próprio aprendizado, quanto a importância da troca de conhecimento e da preservação do meio ambiente. Como sugestões de alteração na ação, dois participantes citaram a possibilidade de levar este modelo para escolas, um participante sugeriu o acréscimo de rede de apoio e/ou de parcerias ambientais para serem citadas durante a roda de conversa e um participante citou a necessidade de ampliação da divulgação, bem como do material de apoio. 


\section{Discussão}

$\mathrm{Na}$ presente investigação, a maior parte dos visitantes do zoológico entrevistados tinham idade entre 21 e 40 anos e eram do sexo feminino. Já em uma pesquisa de Aragão (2014), foram entrevistados 64 visitantes adultos de um zoológico, sendo que estes tiveram faixa etária bem distribuída entre $18 \mathrm{e}$ 50 anos e $61 \%$ era do sexo feminino. Desse modo, verifica-se que os estudos encontraram um perfil similar dos visitantes, fato que pode ser explicado por ambos terem sido coletados no final de semana, dias nos quais o público adulto também frequenta os zoológicos por disponibilidade de tempo e como lazer com a família.

Foi verificado no estudo que a maior parte dos visitantes relataram já ter visitado o parque ecológico. Em uma pesquisa realizada em um zoológico foi observado que dos $84 \%$ visitantes que já conheciam o local 90,5\% relataram que já conheciam por meio da visita (FARINON; NASCIMENTO; IVANKIO, 2014). Em ambos os estudos os visitantes relataram, portanto, já conhecer o local. Esse dado merece atenção ao se questionar a percepção dos indivíduos sobre o ambiente, pois estes levam em consideração como se sentem em relação ao meio em que se encontram, as lembranças que o mesmo lhe remete e as mudanças positivas e negativas que ocorrem ao longo do tempo.

De acordo com Martins, Rancura e Oliveira (2016), para que a EA permita o compartilhamento de conhecimentos e promova a consciência crítica dos sujeitos, ela deve ser participativa, ou seja, possibilitar a troca de informações entre o sujeito e o pesquisador e promover o sentimento de pertencimento nos indivíduos. Na presente investigação, a ação educativa realizada com os visitantes do Parque Ecológico foi feita por meio de uma roda de conversa na qual os pesquisadores permitiram e incentivaram os sujeitos à dialogarem e compartilharem informações. Assim, é importante que a EA seja realizada de modo que haja participação de ambas as partes propiciando um ambiente acolhedor, para que ocorra uma melhor sensibilização acerca da preservação do meio ambiente.

A ação educativa realizada no parque ecológico não levou em consideração apenas questões relacionadas às espécies, mas ao meio ambiente em geral. Segundo Furtado e Branco (2003), o zoológico, além de servir para a conservação e preservação de espécies, deve também, auxiliar como um complemento educativo da Educação Ambiental. Além disso, a criação do presente Parque Ecológico teve como intuito ser um refúgio e símbolo de preservação para o bioma predominante na região, o cerrado. 0 espaço possui não somente espécies animais em recinto, como também animais que transitam livremente pelo espaço e uma rica vegetação.

A ação educativa foi realizada em um dia do fim de semana, para alcançar visitantes de diferentes faixas etárias, visto que segundo Aragão (2014), a maioria das atividades educativas dentro dos zoológicos são realizadas para o público infantil durante visitas escolares durante a semana, 
desse modo evidencia-se a necessidade de realizá-las também aos finais de semana com todos os visitantes e entender quais as necessidades e desejos do público adulto naquele local.

Uma limitação da realização da ação de EA foi em relação ao fato de os participantes terem sido convidados e, por isso, demonstram então um interesse na área, tendo uma percepção pré-estabelecida acerca da importância em se estabelecer diálogos a respeito da Educação Ambiental.

\section{Conclusões}

A partir do diagnóstico realizado foi possível verificar a percepção dos visitantes e dos funcionários em relação à um parque ecológico no interior de São Paulo. O maior percentual dos entrevistados acredita que o parque ecológico é importante por questões de preservação e pelo serviço que realiza, além disso a percepção em geral foi positiva, ressaltando qualidades do local. Foram identificados como pontos a melhorar a gestão e infraestrutura do parque.

Em relação à ação educativa ambiental, os participantes a julgaram como satisfatória quanto a sua finalidade de gerar conhecimento e sensibilizar a população quanto a importância da preservação do meio ambiente e como ela pode ocorrer no espaço em questão, tendo, portanto, alcançado o objetivo proposto.

Desse modo, verificar a percepção de funcionários e visitantes de um zoológico, bem como realizar ações educativas no mesmo pode proporcionar o desenvolvimento de ações eficazes para conscientização acerca da importância da preservação do meio ambiente e dos animais, além de permitir que o presente zoológico conheça a opinião de seus usuários e sua equipe de trabalho. Os resultados do presente trabalho podem contribuir também para o aprimoramento de políticas públicas a fim de realizar a promoção do conhecimento e a sensibilização da população sobre a preservação do meio ambiente.

\section{Agradecimentos}

Ao Parque Ecológico municipal Dr. Antônio Teixeira Vianna, no município de São Carlos, por permitir a realização desse estudo no local. 


\section{Referências}

ALMEIDA, P.A.; FERNÁNDEZ, B.G.; STRECHT-RIBEIRO, O. Children's Opinions about Zoos: A Study of Portuguese and Spanish. Anthrozoös, v.30, n.3, p.457-472, 2017.

ARAGÃO, G.M.O. Percepção ambiental de visitantes do zoológico de BrasíliaDF. Dissertação de mestrado em Agroecossistemas. Universidade Federal de Santa Catarina, 2014.

BARDIN, L. Análise de conteúdo. Lisboa: Edições, 1977.

BARRETO, R.M. et al. Parque Governador José Rollemberg Leite, Aracaju (SE): uma análise da percepção de seus visitantes. Revista brasileira de Educação Ambiental, v.14, n.2, p.328-342, 2019.

BARRETO, K.F.B.; GUIMARÃES, C.R.P.; OLIVEIRA, I.S.S. O zoológico como recurso didático para a prática da Educação Ambiental. Revista Entreideias: Educação, Cultura e Sociedade, n.15, p. 79-91, 2009.

DIAS, A.A.; DIAS, S.M.O. Educação Ambiental: a agricultura como modo de sustentabilidade para a pequena propriedade rural. Revista de Direitos Difusos, Rondônia, v. 68, p. 161-178, 2017.

DIAS, G.F. Educação Ambiental: princípios e práticas. São Paulo: GAIA, 2003.

FARINON, C.L.; NASCIMENTO, E.L.; IVANKIO, R. Avaliação da prática da Educação Ambiental no Zoológico Bosque Guarani no município de Foz de Iguaçu - Paraná. Trabalho de Conclusão de Curso. Universidade Tecnológica Federal do Paraná, 2014.

FISCHER, M.L. et al. Os zoológicos sob a perspectiva da bioética ambiental: uma análise a partir do estudo de caso dos felídeos cativos. Revista Iberoamericana de Bioética, n. 4, p. 1-17, 2017.

FURTADO, M.H.B.C.; BRANCO, J.O. A percepção dos visitantes dos zoológicos de Santa Catarina sobre a temática ambiental. Anais do II Simpósio Sul Brasileiro de Educação Ambiental. UNIVALI / Itajaí, SC, 2003.

FPZSP. Fundação Parque Zoológico de São Paulo. 2015.

IBAMA. Como o IBAMA exerce a Educação Ambiental. Coordenação Geral de Educação Ambiental. Brasília: Edições IBAMA, 2005.

GRAJAL, A. et al. The complex relationship between personal sense of connection to animals and self-reported proenvironmental behaviors by zoo visitors. Conservation Biology, v.31, n.2, p.322-330. 2016.

HSU, Y.H. Learning beyond schools: nonformal Environmental Education in Taiwan. Japanese Journal of Environmental Education, v. 26, n.4, p.33-38, 2017. 
MARTINS, C.; RANCURA, K.G.O.; OLIVEIRA, H.T. As metodologias participativas no processo de elaboração de espaços educadores em zoológicos em uma perspectiva de Educação Ambiental crítica. Rev. Eletrônica Mestr. Educ. Ambient, v. 33, n.1, p. 307-326, 2016.

MOSS, A.; JENSEN, E.; GUSSET, M. Evaluating the contribution of zoos and aquariums to Aichi Biodiversity Target 1. Conservation Biology, v.29, n.2, p.537-544, 2015.

PRA TURISTA. Zoológico de São Carlos-SP. 2019. Disponível em: $<$ https://praturista.com/zoologico-de-sao-carlos-sp/>. Acesso em 09/01/2020.

RANCURA, K.G.O. et al. Contribuições do projeto de Educação Ambiental "clube tetéia" da fundação parque zoológico de São Paulo para o envelhecimento ativo e a inclusão social de idosos. Revista Brasileira de Educação Ambiental, v.11, n.4, p.269-288, 2016.

SILVA, R.L.C.; GARCIA, L.C.F. Enriquecimento ambiental nos zoológicos brasileiros. Atas de Saúde Ambiental (São Paulo, online), v.7, p.157-171, 2019. 